ISSN 0258-7122

Bangladesh J. Agril. Res. 37(3): 465-472, September 2012

\title{
SCREENING OF MUSKMELON (Cucumis melo L.) GERMPLASM AGAINST SALINITY
}

\author{
M. A. MALEK, M. OBAIDUL ISLAM, \\ M. MAMTAZUL HAQUE AND M. K. SULTAN
}

\begin{abstract}
Out of 78 germplasm of muskmelon (Cucumis melo L.), 67 germplasm (86\%) survived against high salinity $(13.82 \mathrm{ds} / \mathrm{m})$ when screened at Benarpota, Satkhira, Khulna. These germplasm showed morphological variations in growth habit, leaf lobes, leaf pubescence, fruit shape, fruit ribs, fruit skin texture, flesh colour, flesh flavor, flesh texture, fruit splitting, fruit aroma, fruit size, seed coat colour, fruit skin colour at fully formed fruit and fruit skin colour at seed harvest maturity. The other qualitative characters, such as tendrils and flowering habit did not show morphological variations. Quantitative variations were observed in leaf length, leaf width, days to staminate flowering, days to pistillate flowering, fruit length, fruit width, fruit weight, number of fruits per plant, flesh thickness, number of seeds per fruit, days to fruit harvest and 1000-seed weight. Among the germplasm, BD-2255 and BD-9159 had no splitting of fruits. Therefore, these two germplasm can be selected for this trait. The characters, such as number fruits per plant and fruit weight exhibited highest number of fruits per plant (21) and maximum fruit weight $(6.25 \mathrm{~kg})$. These two characters should also be considered for improvement of muskmelon. Highest CV (\%) was found in number of fruits per plants (36.35) followed by fruit weight (33.86).
\end{abstract}

Keywords: Muskmelon, germplasm, screening, salinity.

\section{Introduction}

Salinity is a serious environmental constraint to crop production in many parts of the world (Maranville et al., 1993). Estimates for the extent of salinity damage vary from 25 to 50 percent of the worlds irrigated land (Postel, 1989; Adams and Hughes, 1990). In Bangladesh, about 2.83 million ha of land is affected by various degrees of salinity, and efforts are being made to bring the saline areas under cultivation (Begum et al., 2000). Crop culture on such land thus becomes an important step by screening the salt tolerant cultivar (Begum et al., 2000). Soil salinity has become a major factor limiting crop productivity worldwide, especially in arid and semi-arid regions. High salt concentration in the soil solution is bound to create high osmotic pressure in the root zone and reduce availability of water and nutrients to plants. Such conditions are known to affect plant physiological activities, which determine crop yield (Hebbara et

Plant Genetic Resources Centre, Bangladesh Agricultural Research Institute (BARI), Gazipur 1701, Bangladesh. 
al., 2003). Muskmelon is a minor but the most common fruit crop of cucurbitaceae family in Bangladesh. It is grown almost every districts of Bangladesh. Immature melons are used fresh in salads, cooked (soup, stew, curry, stir-fry) or pickled. Mature fruits are eaten fresh as a desert fruit, canned or used for syrup or jam, dehydrated slices (lightly processed) for short-term or moderate storage can be reconstituted, and the pressed juice can be canned. Fruit flesh is usually orange but sometimes green. Its flavour is aromatic. Monoecious and andro-monoecious are most common in muskmelon. Two major genes $A$ and $G$ control sex expression in muskmelon (Vijay, 1987). It grows well in optimum soil $\mathrm{pH} 6.3$ to 6.8. Muskmelon is best stored at 3 to $5^{\mathrm{O}} \mathrm{C}$ with a high relative humidity of $95 \%$. It may be direct seeded or transplanted. Wide variations are present in muskmelon so special attention should be given to its improvement. In these circumstances, the present study was undertaken to evaluate the germplasm of muskmelon against salinity in natural crop management system at saline zones in Benarpota, Satkhira, Khulna to identify the tolerant ones.

\section{Materials and Method}

Seventy eight germplasm of muskmelon were planted on 28 February 2008 at Benarpota, Satkhira, Khulna for screening of germplasm against salinity. These germplasm were collected from different districts of Bangladesh (Table 1). The seedling of each germplasm was raised in poly bags. The 25 days old seedlings of each germplasm were planted in the field maintaining plot size $2.0 \mathrm{~m}$ spacing between the plants. Two plants of each germplasm were maintained in single pit. Recommended fertilizer dose was applied. Urea $50 \mathrm{~g}$, Muriate of Potash (MP) $105 \mathrm{~g}$ and Triple Super Phosphate (TSP) $80 \mathrm{~g}$ were applied in each pit as basal dose during final land preparation. The second dose of urea $50 \mathrm{~g}$ was applied after 35 days of planting. Five irrigations were given at different dates (5.03.2008, 19.03.2008, 26.03.2008, 5.04.2008, and 20.04.2008) during cropping period. Necessary intercultural operations were followed.

May 5 was the last date of fruit harvest. Within this time highest salinity level was recorded as $13.82 \mathrm{ds} / \mathrm{m}$ and the plants of each germplasm was in good condition. Crop duration of each germplasm was 88 days.

Both qualitative and quantitative observations were recorded according to IBPGR (International Board for Plant Genetic Resources) descriptors. Pertinent data on temperature $\left({ }^{\circ} \mathrm{C}\right)$, rainfall $(\mathrm{mm})$ and humidity $(\%)$ and salinity level (ds/m), soil moisture (\%) and soil $\mathrm{pH}$ of Benarpota station is presented in Table 4 and 5, respectively. 
Table 1. Sources or places of collection of $\mathbf{7 8}$ muskmelon germplasm.

\begin{tabular}{|c|c|c|c|c|c|}
\hline Sl. No. & Germplasm & District & Sl. No. & Germplasm & District \\
\hline 1 & BD-2255 & Kusthia & 40 & BD-2298 & Comilla \\
\hline 2 & BD-2256 & Kusthia & 41 & BD-2299 & Comilla \\
\hline 3 & BD-2257 & Kusthia & 42 & BD-2300 & Comilla \\
\hline 4 & BD-2258 & Kusthia & 43 & BD-2301 & Comilla \\
\hline 5 & BD-2259 & Kusthia & 44 & BD-2302 & Sirajganj \\
\hline 6 & BD-2260 & Kusthia & 45 & BD-2303 & Sirajganj \\
\hline 7 & BD-2261 & Kusthia & 46 & BD-2304 & Sirajganj \\
\hline 8 & BD-2262 & Kusthia & 47 & BD-2305 & Sirajganj \\
\hline 9 & BD-2263 & Kusthia & 48 & BD-2306 & Sirajganj \\
\hline 10 & BD-2264 & Kusthia & 49 & BD-2307 & Sirajganj \\
\hline 11 & BD-2265 & Kusthia & 50 & BD-2308 & Sirajganj \\
\hline 12 & BD-2266 & Kusthia & 51 & BD-2309 & Sirajganj \\
\hline 13 & BD-2267 & Kusthia & 52 & BD-2310 & Sirajganj \\
\hline 14 & BD-2268 & Kusthia & 53 & BD-2311 & Sirajganj \\
\hline 15 & BD-2270 & Chuadanga & 54 & BD-2312 & Chittagong \\
\hline 16 & BD-2271 & Chuadanga & 55 & BD-2313 & Chittagong \\
\hline 17 & BD-2272 & Chuadanga & 56 & BD-2314 & Pabna \\
\hline 18 & BD-2273 & Chuadanga & 57 & BD-2315 & Pabna \\
\hline 19 & BD-2275 & Chuadanga & 58 & BD-2316 & Pabna \\
\hline 20 & BD-2276 & Faridpur & 59 & BD-2317 & Pabna \\
\hline 21 & BD-2277 & Faridpur & 60 & BD-2318 & Naogaon \\
\hline 22 & BD-2280 & Faridpur & 61 & BD-2319 & Naogaon \\
\hline 23 & BD-2281 & Faridpur & 62 & BD-2320 & Naogaon \\
\hline 24 & BD-2282 & Rajshahi & 63 & BD-2321 & Naogaon \\
\hline 25 & BD-2283 & Chittagong & 64 & BD-2322 & Kusthia \\
\hline 26 & BD-2284 & Chittagong & 65 & BD-2323 & Kusthia \\
\hline 27 & BD-2285 & Jamalpur & 66 & BD-7442 & Jessore \\
\hline 28 & BD-2286 & Jamalpur & 67 & BD-8888 & IPK-Germany \\
\hline 29 & BD-2287 & Mymensingh & 68 & BD-8889 & Barishal \\
\hline 30 & BD-2288 & Mymensingh & 69 & BD-9149 & Kusthia \\
\hline 31 & BD-2289 & Mymensingh & 70 & BD-9151 & Jamalpur \\
\hline 32 & BD-2290 & Tangail & 71 & BD-9154 & Pabna \\
\hline 33 & BD-2291 & Tangail & 72 & BD-9155 & Pabna \\
\hline 34 & BD-2292 & Tangail & 73 & BD-9156 & Sreepur \\
\hline 35 & BD-2293 & Tangail & 74 & BD-9157 & Gazipur \\
\hline 36 & BD-2294 & Tangail & 75 & BD-9158 & Natore \\
\hline 37 & BD-2295 & Tangail & 76 & BD-9159 & Chapainwabganj \\
\hline 38 & BD-2296 & Tangail & 77 & BD-9160 & Rajshahi \\
\hline 39 & BD-2297 & Tangail & 78 & $\mathrm{~T}-307$ & Kusthia \\
\hline
\end{tabular}




\section{Results and Discussion}

Seventy eight germplasm of muskmelon (Cucumis melo L.) were planted in Benarpota, Satkhira, Khulna. Among them, 67 germplasm (86\%) survived against high salinity (13.82 ds/m). The 8 germplasm viz. BD-2280, BD-2283, BD-2294, BD-2300, BD-2302, BD-2303, BD-2308, and BD-2319 died after 18 days at $8.43 \mathrm{ds} / \mathrm{m}$ salinity and 3 germplasm, such as BD-2286, BD-2311, and BD-2316 died after 32 days of planting at $12.85 \mathrm{ds} / \mathrm{m}$.

\section{Morphological characterization}

Morphological variations of 67 musk melon germplasm for different characters are presented in Table 2. All the germplasm of muskmelon showed morphological variations for all the characters except tendrils and flowering habit. These two characters showed no morphological variations. All the germplasm had tendrils and monoecious flower in nature.

The highest variability was observed in fruit skin colour (at fully formed fruit) viz. green-19, light green-1, cream-3, orange-1, pink-4, grey-3, and black35 . In case of growth habit, bushy-18, intermediate-31, and prostrate-18 were found in the germplasm followed by fruit skin texture viz. smooth-37, grainy-8, finely wrinkled-1, shallowly wavy-5, netted-3 and with spines-13. For leaf lobes, no leaf lobes-10, shallow-12, intermediate-29 and deep leaf lobes-16 were observed. Among the germplasm, three types of intensity of leaf pubescences, such as glabrous-17, sparse-31, and dense-19 were found. Ellipsoid-2, oblong ellipsoid-48, globular-9, and stem-end tapered-5 for fruit shape were observed among the germplasm. In case of fruit ribs, no fruit ribs-4, superficial ribs-27 and deep fruit ribs-36 were recorded. Three types of flesh colour, such as white-25, yellow-3, and orange-39 were observed among the germplasm. Insipid-50, intermediate- 11 and sweet- 6 were found for flesh flavour. In case of flesh texture, smooth fruit-34 and grainy firm-33 were exhibited in the germplasm. For fruit splitting, no splitting-2, superficial-5 and deep splitting-60 was observed. Among the germplasm, no fruit aroma-48, external only-2, internal only-15 and both external and internal fruit aroma-2 were observed. In case of fruit skin colour (at seed harvest), cream-2, yellow-27, orange-3, grey-2 and black-33 were found among the germplasm. Different types of fruit size viz. small-6, medium20 and large fruit- 41 were observed in the germplasm. Some germplasm showed white-58 and orange-9 was recorded for seed coat colour.

Splitting of the muskmelon fruit is an important character for marketing. Due to splitting of fruit, it is difficult to transport from one place to another. In this study, two germplasm such as BD-2255 and BD-9159 were found of no splitting type. Therefore, these germplasm can be selected for improvement of muskmelon. 
Table 2. Number of muskmelon germplasm under different classes in salinity condition.

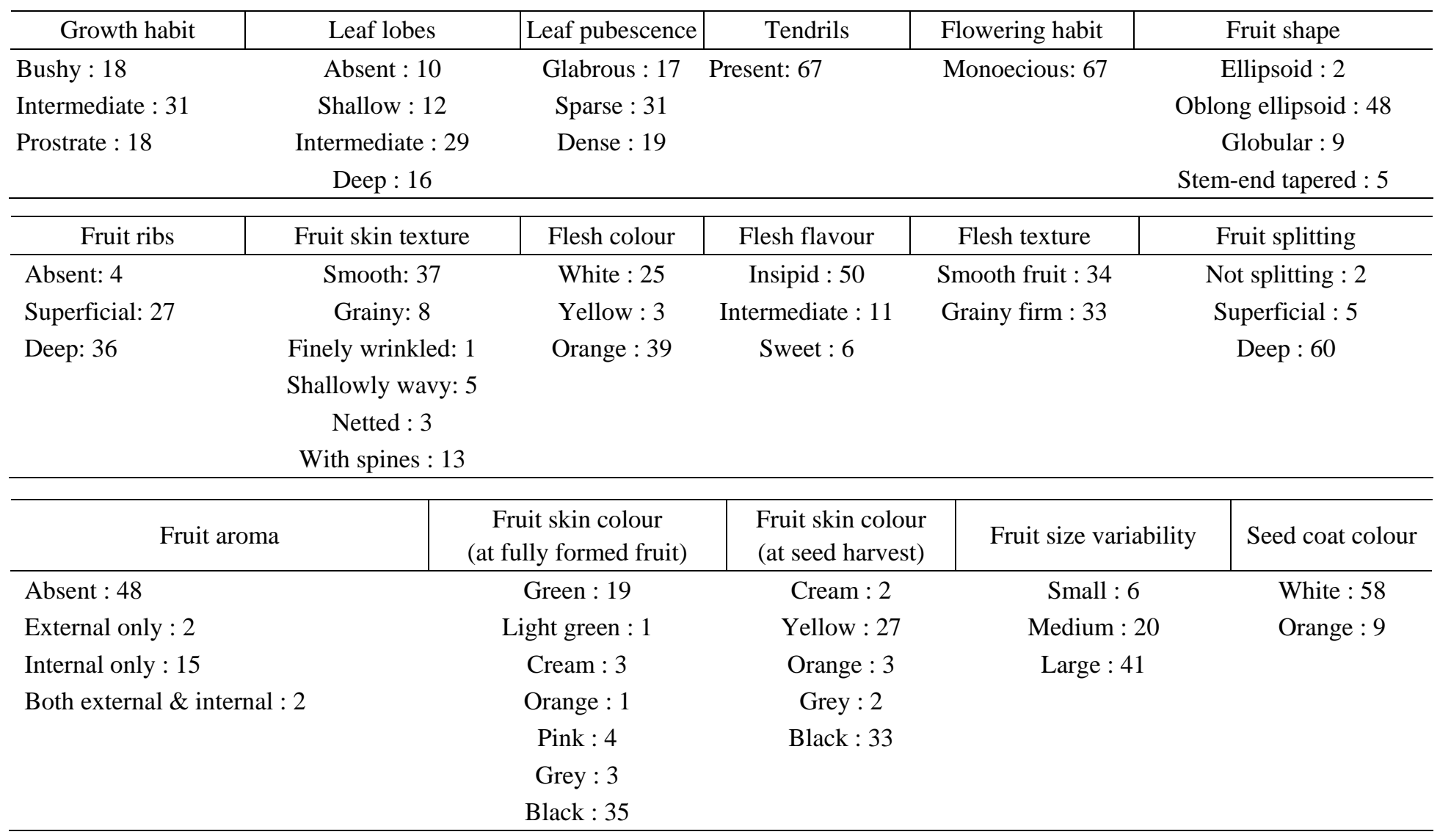




\section{Quantitative characterization}

The quantitative variations were observed in days to staminate flower, days to pistillate flower, fruit length $(\mathrm{cm})$, fruit width $(\mathrm{cm})$, fruit weight $(\mathrm{kg})$, number of fruits per plant, flesh thickness (cm), number of seeds per fruit, 1000-seed weight (g), days to $1^{\text {st }}$ harvest and days to final harvest (Table 3). Days to staminate flower ranged from 21 (BD-2268 and BD-2281) to 57 (BD-2263, BD-2310 and BD-9151) days. In case of days to pistillate flower ranged from 26 (BD-2260) to 62 (BD-2263, BD-2264, BD-2287, BD-2310 and BD-9151) days. The germplasm BD-2268 (52 days) and BD-2255 (55 days) were found as early variety on the basis of harvesting time of the fruit. These two germplasm required only 52 and 55 days to harvest, respectively. While the germplasm BD-2263 and BD-2287 (85 days), and BD-8889 (83 days) were observed as late variety on the basis of days to pistillate flowering and harvesting time of the fruit.

\section{Mean, range, standard deviation and co-efficient of variation}

Range, mean, standard deviation and co-efficient of variation are shown in Table 3. Wide variations were observed for all the characters except flesh thickness, days to 1st harvest, days to final harvest and 1000-seed weight (Table 3). These four characters exhibited the minimum range of estimates with a general mean indicating narrow range of variability.

Maximum range of variation were found in days to staminate flower (21-57 days), days to pistillate flower (26-62 days), fruit length $(12.60-50.32 \mathrm{~cm})$, fruit width (23.20-52.00 cm), fruit weight (1.40-6.25 kg), number fruits per plant (421 ), number of seeds per fruit (345-815), 1000-seed weight $(\mathrm{g})$, and days to $1^{\text {st }}$ harvest (52-85 days) indicating remarkable variations were present among the germplasm. Highest number of fruits per plant (21) was recorded in BD-2268 and second highest (20) in BD-2291. Highest CV\% was observed in number of fruits per plant (36.35) followed by fruit weight (33.86).

The number of fruits per plant and fruit weight exhibited the maximum range of variation (4-21and 1.40-6.25) with a mean of 10.46 and 2.75, respectively. Characters, which showed high range of variation, should be given priority in the selection (Vijay, 1987). While the range of variation was low for the characters indicated narrow range of variability among the germplasm and suggested that selection would not be effective for these traits. Among the germplasm, BD-2255 and BD-9159 were found as non-splitting type. Therefore, these two germplasm can be selected for this trait. In addition, the characters such as number fruits per plant and fruit weight should also be considered for improvement of muskmelon. All the 67 germplasm were rated as tolerant against the salinity level of 13.82 $\mathrm{ds} / \mathrm{m}$. 
Table 3. Range, mean, standard deviation and CV\% of muskmelon in salinity condition $(13.82 \mathrm{ds} / \mathrm{m})$.

\begin{tabular}{lcccccc}
\hline \multicolumn{1}{c|}{ Character } & $\begin{array}{c}\text { No. of } \\
\text { observation }\end{array}$ & Range & Mean & Sd. & CV\% \\
\hline $\begin{array}{l}\text { Days to staminate } \\
\text { flower }\end{array}$ & 67 & $21-57$ & 41.34 & 12.07 & 29.19 \\
$\begin{array}{l}\text { Days to pistillate } \\
\text { flower }\end{array}$ & 67 & $26-62$ & 46.37 & 11.69 & 25.22 \\
Fruit length (cm) & 67 & $12.60-50.32$ & 29.57 & 6.36 & 21.49 \\
$\begin{array}{l}\text { Fruit width (cm) } \\
\text { Fruit wt (kg) }\end{array}$ & 67 & $23.20-52.00$ & 36.08 & 6.17 & 17.09 \\
No. of fruits/plant & 67 & $1.40-6.25$ & 2.75 & 0.93 & 33.86 \\
Flesh thickness & 67 & $4-21$ & 10.46 & 3.80 & 36.35 \\
No. of seeds/fruit & 67 & $1.80-3.20$ & 2.56 & 0.30 & 11.82 \\
1000-seed wt (g) & 67 & $35.00-63.00$ & 48.51 & 5.39 & 11.13 \\
Days to $1^{\text {st }}$ harvest & 67 & $52-85$ & 68.64 & 7.75 & 11.29 \\
Days to final harvest & 67 & $70-88$ & 77.75 & 5.77 & 7.42 \\
\hline
\end{tabular}

Table 4. Monthly temperature $\left({ }^{\circ} \mathrm{C}\right)$, rainfall $(\mathrm{mm})$ and humidity $(\%)$ during cropping period.

\begin{tabular}{l|cc|c|c}
\hline \multirow{2}{*}{ Month } & \multicolumn{2}{|c|}{ Temperature $\left({ }^{\circ} \mathrm{C}\right)$} & \multirow{2}{*}{ Rainfall (mm) } & \multirow{2}{*}{ Humidity (\%) } \\
\cline { 2 - 3 } & Maximum & Minimum & & 304.27 \\
\hline January & 25.26 & 11.83 & 0 & 313.12 \\
February & 27.10 & 16.86 & 112 & 275.39 \\
March & 30.67 & 18.70 & 18 & 298.02 \\
April & 34.29 & 24.83 & 121 & 289.82 \\
May & 35.50 & 26.27 & 30 & \\
\hline
\end{tabular}

Table 5. Date wise salinity (ds/m), soil moisture (\%) and soil pH during cropping period.

\begin{tabular}{r|c|c|c}
\hline Date & Salinity $(\mathrm{ds} / \mathrm{m})$ & Soil moisture $(\%)$ & Soil $\mathrm{pH}$ \\
\hline 28.02 .2008 & 4.50 & 10.00 & 7.30 \\
10.03 .2008 & 8.24 & 9.75 & 6.70 \\
25.03 .2008 & 8.90 & 21.85 & 6.50 \\
10.04 .2008 & 8.52 & 19.35 & 7.30 \\
24.04 .2008 & 5.10 & 7.00 & 7.20 \\
10.05 .2008 & 13.82 & 7.50 & 7.00 \\
25.05 .2008 & 12.67 & 16.00 & 6.80 \\
\hline
\end{tabular}




\section{References}

Adams, W.M and F.M.R Hughes. 1990. Irrigation development in desert environments. In: Techniques for Desert Reclamation. AS. Goudie (ed.). John Wiley, New York. pp. $35-160$.

Begum, F., Bimal Chandra Sarker and Sirajul Hoque. 2000. Effects of salinity on growth and accumulation of $\mathrm{Na}^{+}, \mathrm{K}^{+}$and $\mathrm{Cl}^{-}$in Maize (Zea mays). Dhaka Uni. J. Biol. Sci. 9 (2): 193-196.

Hebbara, M., G. R. Rajakumar, G. Ravishankar and C. V. Raghavaiah. 2003. Effect of salinity stress on seed yield through physiological parameters in sunflower genotypes. Hella 26. Nr.39. pp.155-160.

Maranville, J.W., B.V. Baligar, R.R. Duncan \& J.M. Yohe (eds.). 1993. Proc. Workshop on Adaptation of Plants to Soil Stresses. p. 117-132. In: INTSORMIL. Pub. No. 94-2, Univ. of NE, Lincoln, NE, August l-4, 1993.

Postel, S. 1989. Water for agriculture: Facing the limits. Worldwatch Paper 93. Worldwatch Institute, Washington DC.

Vijay, O. P. 1987. Genetic variability, correlation and path analysis in muskmelon (Cucumis melo L.). Indian J. Hort. 44 (4): 233-238. 